\title{
Oral findings in Rett syndrome: An update and review of the literature
}

\section{Zmiany w jamie ustnej w zespole Retta - przegląd współczesnego piśmiennictwa}

\author{
Edoardo Bianco ${ }^{A-C, E, F}$, Denise Rota ${ }^{D, F}$ \\ Department of Surgery and Translational Medicine, University of Milano-Bicocca, Milan, Italy \\ A - research concept and design; $\mathrm{B}$ - collection and/or assembly of data; $\mathrm{C}$ - data analysis and interpretation; \\ $D$ - writing the article; $E$ - critical revision of the article; $F$ - final approval of the article
}

Address for correspondence

Edoardo Bianco

E-mail: eduardowhite@gmail.com

Funding sources

None declared

Conflict of interest

None declared

Received on July 5, 2018

Reviewed on September 7, 2018

Accepted on October 25, 2018

Published online on December 17, 2018

\begin{abstract}
Rett syndrome is a progressive pediatric neurodevelopmental disorder, predominantly affecting females, characterized by a seemingly normal prenatal and perinatal period, followed by neurodevelopmental stagnation, and then rapid regression.

The purpose of this study was to provide an update of the literature on the oral aspects of Rett syndrome and their possible treatment in patients suffering from this pathology. After an electronic and manual search in MEDLINE (PubMed) and the Cochrane Library, 12 articles were found, for a total of 142 patients affected by Rett syndrome. A high prevalence of bruxism, anterior open bite, ogival palate, sucking habits, and difficulties in maintaining oral hygiene was noted. There were also oral findings related to the pharmacological treatment, which included xerostomia, glossitis, erythema multiforme, gingival hyperplasia, dysphagia, and lingual paralysis. It is important for the dentist to know what problems related to the oral cavity can be encountered in a patient diagnosed with Rett syndrome and what preventive measures can be applied.
\end{abstract}

Key words: autism, bruxism, Rett syndrome, oral manifestations

Słowa kluczowe: autyzm, bruksizm, zespół Retta, objawy w jamie ustnej

Cite as

Bianco E, Rota D. Oral findings in Rett syndrome: An update and review of the literature. Dent Med Probl. 2018;55(4):441-445. doi:10.17219/dmp/99203

DOI

$10.17219 / \mathrm{dmp} / 99203$

Copyright

(c) 2018 by Wroclaw Medical University

and Polish Dental Society

This is an article distributed under the terms of the

Creative Commons Attribution Non-Commercial License

(http://creativecommons.org/licenses/by-nc-nd/4.0/) 


\section{Introduction}

Rett syndrome is a progressive pediatric neurodevelopmental disorder, which was first described by Andreas Rett in 1966. It is an X chromosome-linked condition, which almost exclusively affects females. The estimated prevalence of the disorder ranges from 1:10000 to 1:15000 in newborns. ${ }^{1}$

Rett syndrome is a neurodegenerative disease, characterized by a seemingly normal prenatal and perinatal period and healthy development for 6-18 months, followed by a period of neurodevelopmental stagnation, and then rapid regression: loss of previously acquired speech, cognitive skills, purposeful hand skills, and active play interest. A further deterioration of cognitive abilities leads to autistic-like attitudes, mental delay and motor disturbances like ataxia, apraxia and tremor. Seizures, stereotypical movements of the hands, hyperventilation, and periods of apnea when awake are also common. ${ }^{2-4}$ Progressive muscle atrophy of the distal arms and legs, weight loss, growth retardation, and kyphosis can also be found.,3

In 1999, some mutations in the methyl-CpG-binding protein 2 gene ( $M e C P 2$, a transcriptional regulator gene) were identified as the causes of the condition, even if some rarer mutations in other genes could be found, particularly in CDKL5 in the infantile seizure onset variant and FOXG1 in the congenital variant. ${ }^{5-8}$

Only a few studies on the oral signs and symptoms of Rett syndrome can be found, and there are no up-to-date literature reviews on the oral manifestations in these patients. The purpose of this study was to provide an update of the literature on the oral aspects of Rett syndrome and their possible treatment in patients suffering from this pathology.

\section{Material and methods}

An electronic search in MEDLINE (PubMed) and the Cochrane Library of publications from January 1985 to September 2017 was performed using the following search terms: [rett syndrome] AND [oral OR dental OR dentist OR bruxism]. Moreover, a manual search of the bibliographies of all full text articles was also conducted.

The selected studies had to meet the following inclusion criteria:

- publications in English and Italian in the dental literature;

- case reports, case series and reviews that clearly describe the oral manifestations or dental feedback or problems related to dentistry in patients with Rett syndrome, or clinical case studies with the description of the provided dental treatment.

Research papers that did not clearly describe the signs and symptoms of Rett syndrome, or did not specify the provided dental treatment were excluded from the study.

\section{Results}

The research identified 12 articles, for a total of 142 patients affected by Rett syndrome.

It was decided that case reports would also be included in the review, since, taking into consideration the scarcity of studies on this topic, it was regarded important to make the spectrum of cases to be reviewed as wide as possible.

The first analyzed case of dental treatment applied to patients with Rett syndrome, described in the literature, regarded the endodontic treatment of a superior central incisor, performed under general anesthesia in a 12-year-old patient. ${ }^{9}$ The treatment was implemented after a facial trauma, which occurred during a seizure. Among the analyzed articles, this was the only one that reported dental treatment caused by a facial trauma in a patient with Rett syndrome. ${ }^{9}$

Pagnacco et al. presented the case of a 5-year-old girl with caries of the deciduous dentition, dental wear and abundant sialorrhea ${ }^{10}$; in this case, dental treatment was also carried out under general anesthesia due to the impossibility of providing care on an outpatient basis.

What is clear from our analysis is that the most frequent oral manifestations in Rett syndrome are bruxism, multiple cavities and drooling.

Coleman et al., in a 1988 study, reported evidence of bruxism in $95 \%$ of 63 patients with Rett syndrome, as well as atypical swallowing in $65 \%$ of cases and hypersalivation in $84 \% .^{11}$

Buccino and Weddell, in a case report, emphasized the absence of decay in a 4-year-old child, in whom, however, there were signs of abrasion over all the teeth (particularly of the upper and lower anterior sector teeth) and mobility of grade 2 of teeth 51 and 61 due to bruxism and finger sucking. ${ }^{12}$ These authors also reported hypersalivation, drooling and ogival palate. The prevention of oral disease was the only recommendation made - establishing control of bruxism and traumatism, improving oral hygiene with the help of the parents, daily application of topical fluoride gel or rinses, and frequent follow-up visits.

Peak et al. found bilateral hypertrophy of the masseters and bruxism with widespread signs of abrasion in a 5 -year-old patient. ${ }^{13}$

Furthermore, Magalhães et al., in 13 patients, found bruxism as the only oral symptom of Rett syndrome, without evidence of carious lesions, but with dental abrasion and muscular dysfunction as a consequence of grinding. ${ }^{14}$ In their study, they tried subjecting patients to acupuncture sessions, performed on a weekly basis for an average of 3 years and 4 months in order to reduce grinding habits, but concluded that it was impossible to evaluate the effectiveness of the therapy.

In a case report of a 5-year-old girl, Alpoz et al. showed radiographically an enlargement of the joint space around the temporomandibular joint (TMJ), presumably linked to a considerably retracted position 
of the condyles due to the loss of the vertical dimension, resulting from the strong occlusion. ${ }^{15}$ They treated her with a soft splint, and even a special design of the splint was developed in order to avoid the anterior mandibular movement.

A study of 17 girls affected by Rett syndrome conducted by Ribeiro et al. showed signs of gingivitis with considerable plaque accumulation as well as thumb sucking habits in all patients, and also bruxism in $82 \%$ of cases, non-physiological dental abrasion (more common in the anterior deciduous teeth) in $71 \%$, carious lesions in $59 \%$, ogival palate in $53 \%$, oral breathing in $41 \%$, infant swallowing in $29 \%$, jaw lateralization in $12 \%$, and open bite in more than $80 \%$ of cases together with bruxism and finger sucking. ${ }^{3}$ A single finding by the authors of migrant glossitis in one of the patients cannot be confidently related to Rett syndrome.

Other case reports and studies also highlighted the abovementioned signs. ${ }^{1,4,16,17}$

The most comprehensive systematic review of the dental literature on the subject was presented by Fuertes-González et al., who listed all the oral findings in 35 patients: xerostomia, stomatitis, glossitis, erythema multiforme, sialorrhea, dysgeusia, gingivitis, parotid gland swelling, periodontal abscesses, sinusitis, dysphagia and tongue paralysis due to drugs, digital-manual sucking/nibbling, bruxism, oral breathing, tongue thrusting, dribbling, mandibular lateralization, gingivitis, caries, high-arched palate, open bite, traumatism, dental wear, sialorrhea, and masseter hypertrophy. ${ }^{18}$

In the analyzed studies, great attention was paid to the need for prevention. ${ }^{19}$ Patients with Rett syndrome present with severe psychomotor delay, autistic attitudes and loss of ability to perform controlled voluntary movements. All this results in a difficult management of the patient in terms of providing dental treatment by the dentist and maintaining oral hygiene at home. Therefore, in these patients, prevention procedures are essential. The dentist must implement preventive procedures with frequent follow-ups to monitor bruxism and the onset of possible caries and abrasion. On the other hand, the role of the parents is to ensure fundamental home-based prevention regarding oral hygiene, including frequent application of fluoride gels or systemic fluoride prophylaxis. ${ }^{6}$ Even a diet with few cariogenic foods can help to control carious disease. ${ }^{1}$

Deep carious lesions associated with pain may necessitate follow-up sessions of the compromised teeth under general anesthesia or sedation. ${ }^{4}$

To reduce the problems related to bruxism, associated with dental abrasion and muscular dysfunction, Magalhães et al. suggests the use of modified daytime and nocturnal bites. ${ }^{14}$ The upper dental elements are covered to reproduce the myocentric occlusion and the posterior margin of the bite extends posteriorly to the hard palate. Many authors recommend using a resin bite exclusively during the day, since the sucking habits (oro-digital habits) and the severe degree of mental delay could make it dangerous to use at night. ${ }^{12,15}$ Moreover, these bites cannot be used in patients with deciduous dentition. ${ }^{13}$ In such a case, Chattopadhyay and Arora advise parents to organize frequent visits to the dentist to check the progression of grinding and the hypertrophy of the masseters, and assess the possibility of introducing a bite at an appropriate time. ${ }^{1}$ Friedlander et al. also consider the possible use of myorelaxants or benzodiazepines to control grinding in the most severe cases. ${ }^{19}$

Furthermore, in their study, Friedlander et al. point at another oral manifestation in Rett syndrome - the possible erosion of the surfaces of the teeth, caused by the exposure to acids, consequent upon gastroesophageal reflux, quite common in patients with Rett syndrome. ${ }^{19}$ Among the 12 analyzed studies, only that of Di Bona shows no evidence of diurnal or nocturnal grinding; therefore, it can be concluded that this clinical sign can be found in almost all patients with Rett syndrome. ${ }^{9}$

Ten studies out of 12 investigated the presence or absence of caries, and multiple cavities were found in $37.2 \%$ of patients (29 patients out of 78). These results are indicative only. In the case of younger patients, caries may not yet have arisen because of their early age or the patients simply benefited from excellent oral hygiene put into practice by their caretakers. It should also be noted that in some cases there might be no signs of bruxism due to the young age of the patients. What can be gathered from our review is that, due to the difficulty of obtaining adequate compliancy as well as the possible presence of gastroesophageal reflux, these patients are at a higher risk of developing caries than the rest of the healthy pediatric population. Bruxism seems to be a common finding in a high percentage of patients.

Drooling, deep bite and ogival palate are not reported in all the studies; therefore, a reliable statistical analysis of these problems is difficult. It is not possible to provide accurate data on the percentage of caries, since the patients' age is not a homogeneous variable; consequently, a statistical comparison cannot be made. Moreover, in the analyzed studies, the diagnostic approach to the various dental problems is not uniform.

\section{Discussion}

There are 2 types of oral manifestations associated with Rett syndrome: those related to drugs taken by patients and those derived from Rett syndrome itself.

Among the latter, which are not pathognomonic for the syndrome but rather accompany it, and their prevalence in Rett syndrome patients is higher as compared to the healthy population, we found mainly bruxism, anterior open bite, ogival palate, sucking habits, and difficulties in maintaining oral hygiene (Table 1). 
Table 1. Oral manifestations in Rett syndrome in the analyzed studies

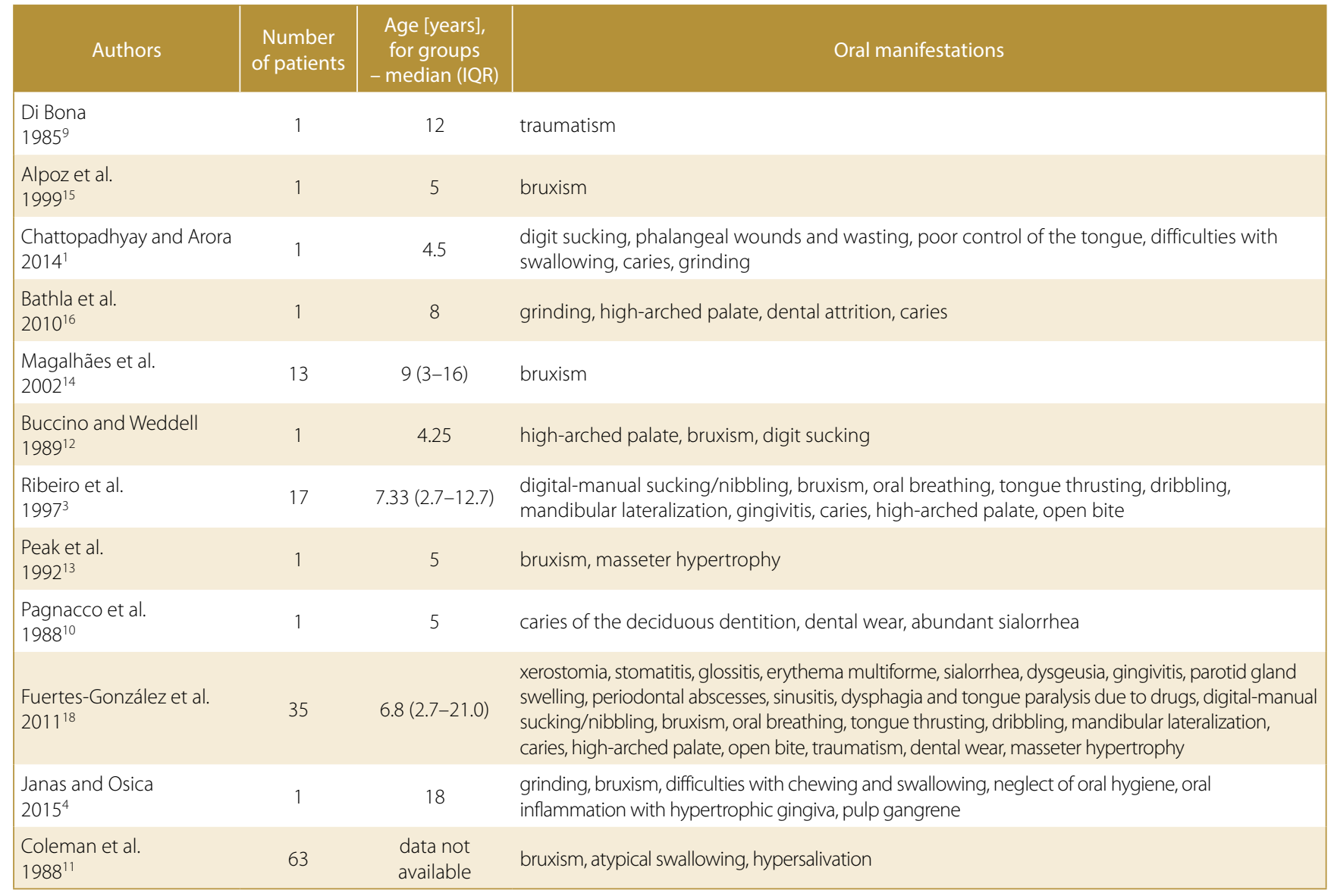

IQR - interquartile range.

The events related to the pharmacological therapies to which these patients are subjected (mainly anxiolytic and anticonvulsant) include xerostomia, glossitis, erythema multiforme, gingival hyperplasia, dysphagia, and lingual paralysis. $^{1,19}$

It is important for the dentist to know what problems related to the oral cavity can be encountered in a patient diagnosed with Rett syndrome and what preventive measures can be applied. To date, there has been no specific type of dental treatment that could be used in these patients; however, prevention is essential. Grinding and the presence of multiple cavities are the most frequent dental findings.

Grinding (more frequently diurnal rather than nocturnal) should be monitored over time to evaluate wear of the dental elements and to decide whether to intervene with a bite. ${ }^{14,19}$ Caries prevention often needs to be done with the help of parents due to the patients' mental delay. Topical fluoride applications are recommended to reduce the risk of caries, as are frequent checks by the attending dentist. ${ }^{11,17}$

When it is necessary to intervene, the literature describes the use of mouth props to secure a degree of stability and oral opening, in order to facilitate dental exploration and/or treatment. As regards behavioral management, some authors suggested the application of certain techniques used in autism (routines and the avoidance of noise). ${ }^{13}$
Some authors used sedation with nitrous oxide,${ }^{15}$ while others combined it with sublingual midazolam. ${ }^{17}$ In turn, some investigators used general anesthesia, ${ }^{11,12}$ due to the medical risk and the lack of the patient's cooperation needed for correct dental treatment. ${ }^{19}$

\section{References}

1. Chattopadhyay S, Arora R. The ironies of human mind: A case of Rett syndrome. Ethiop J Health Sci. 2014;24:171-174.

2. Cianfaglione R, Clarke A, Kerr M, Hastings RP, Oliver C, Felce D. Ageing in Rett syndrome. J Intellect Disabil Res. 2016;60:182-190.

3. Ribeiro RA, Romano AR, Birman EG, Mayer MP. Oral manifestations in Rett syndrome: A study of 17 cases. Pediatr Dent. 1997;19:349-352.

4. Janas A, Osica P. Dental issues in Rett syndrome. Dev Period Med. 2015;19:478-481.

5. Hagberg B, Hanefeld F, Percy A, Skjeldal O. An update on clinically appreciable diagnostic criteria in Rett syndrome. Comments to Rett Syndrome Clinical Criteria Consensus Panel Satellite to European Paediatric Neurology Society Meeting, Baden-Baden, Germany, 11 September 2001. Eur J Paediatr Neurol. 2002;6:293-297.

6. Amir RE, Van den Veyver IB, Wan M, Tran CQ, Francke U, Zoghbi HY. Rett syndrome is caused by mutations in X-linked MECP2, encoding methyl-CpG-binding protein. Nat Genet. 1999;23:185-188.

7. Bienvenu T, Chelly J. Molecular genetics of Rett syndrome: When DNA methylation goes unrecognized. Nat Rev Genet. 2006;7:415-426.

8. Matsuishi T, Yamashita Y, Takahashi T, Nagamitsu S. Rett syndrome: The state of clinical and basic research, and future perspectives. Brain Dev. 2011;33:627-631.

9. Di Bona MC. Hospital dentistry for a child with Rett's syndrome. Spec Care Dent. 1985;5:62-63. 
10. Pagnacco A, Ferrara M, Vangelisti $R$, Randon C. Rett syndrome: A "new" and rare disease. A clinical case [in Italian]. Dent Cadmos. 1988;56:93-95.

11. Coleman M, Brubaker J, Hunter K, Smith G. Rett syndrome: A survey of North American patients. J Ment Defic Res. 1988;32:117-124.

12. Buccino MA, Weddell JA. Rett syndrome - a rare and often misdiagnosed syndrome: Case report. Pediatr Dent. 1989;11:151-157.

13. Peak J, Eveson JW, Scully C. Oral manifestation of Rett's syndrome. BrDent J. 1992;172:248-249.

14. Magalhães MH, Kawamura JY, Araújo LC. General and oral characteristics in Rett syndrome. Spec Care Dent. 2002;22:147-150.

15. Alpoz AR, Ergul N, Oncag O. Bruxism in Rett syndrome: A case report. J Clin Pediatr Dent. 1999;23:161-163.

16. Bathla M, Chandna S, Bathla JC. Rett's syndrome: Diagnostic and therapeutic dilemma. Ger J Psych. 2010;13:157-160.

17. Fuertes-González MC, Silvestre FJ. Oral health in a group of patients with Rett syndrome in the regions of Valencia and Murcia (Spain): A case-control study. Med Oral Patol Oral Cir Bucal. 2014;19:e598-e604.

18. Fuertes-González MC, Silvestre FJ, Almerich-Silla JM. Oral findings in Rett syndrome: A systematic review of the dental literature. Med Oral Patol Oral Cir Bucal. 2011;16:e37-e41.

19. Friedlander AH, Yagiela JA, Paterno VI, Mahler ME. The pathophysiology, medical management and dental implications of fragile $\mathrm{X}$, Rett, and Prader-Willi syndromes. J Calif Dent Assoc. 2003;31:693-702. 
